\title{
Variation of some antioxidant biomarkers in Cameroonian patients treated with first-line anti-tuberculosis drugs
}

\section{Christelle DOMNGANG NOCHE ${ }^{1,2}$, Liliane NGO DIEU ${ }^{1}$, Pascal CHUISSEU DJAMEN ${ }^{3}$, Pierre FOTSING KWETCHE ${ }^{3}$, Walter PEFURA-YONE ${ }^{4}$, Wilfred MBACHAM ${ }^{5,6^{*}}$ and Francois-Xavier ETOA ${ }^{2 *}$}

${ }^{I}$ Department of Clinical Sciences, Higher Institute of Health Sciences, Université des Montagnes, Bangangté, PO. Box 208, Cameroon.

${ }^{2}$ Department of Microbiology, Faculty of Science, Université de Yaounde 1, PO. Box 812, Cameroon.

${ }^{3}$ Department of Basic Sciences, Higher Institute of Health Sciences, Université des Montagnes, Bangangté, PO. Box 208, Cameroon.

${ }^{4}$ Department of Internal Medicine and Subspecialties, Faculty of Medicine and Biomedical Sciences, Université de Yaounde 1, PO. Box 812, Cameroon.

${ }^{5}$ Department of Physiological and biochemical Sciences, Faculty of Medicine and Biomedical Sciences, Université de Yaounde 1, PO. Box 812, Cameroon.

${ }^{6}$ Department of Biochemistry, Faculty of Science, Université de Yaounde 1, PO. Box 812, Cameroon.

"Corresponding authors; E-mail: fxetoa@yahoo.fr/wfmbacham@yahoo.com

\begin{abstract}
M. tuberculosis infection and its treatment are responsible of an oxidative stress response that contribute to the antioxidant/prooxidant imbalance. The analysis of antioxidant biomarkers appears as a potential monitoring tool of the treatment response. The objective of this work was to study the evolution of enzymatic antioxidant biomarkers under the effect of the 1st line antituberculosis therapy. A cohort study, conducted at Jamot Hospital of Yaoundé, took place from February to October 2018. After obtaining an informed consent, clinical parameters were collected and the catalase and SOD activities were assayed in the blood samples from Tuberculosis (TB) patients before treatment (T1), at the end of the $2^{\text {nd }}$ month (T2) and at the $5^{\text {th }}$ month of treatment (T3). There were 50 men and 25 women (mean age: $34+13$ years). Tuberculosis was mainly pulmonary $(85.3 \%)$ with $16 \%$ of HIV-TB co-infected patients and $28 \%$ smokers. Catalase activity varied significantly $(\mathrm{T} 1=3588+244.8 \mathrm{IU} ; \mathrm{T} 2=2541+590.7 \mathrm{IU} ; \mathrm{T} 3=3049+204.4 \mathrm{IU})$ with the lowest threshold at T2 ( $1<0.0001)$ and SOD activity increased from T1 $(0.041+0.021$ IU) to T3 $(0.062+0.040$ IU) $(\mathrm{p}=0.0112)$. There was no influence of disease-related factors (site, duration of signs, microscopy, HIV and smoking status) on both catalase and SOD activities. In the study population, catalase and SOD varied significantly between the pre-treatment and the 5th month of treatment phase. However, the profile of evolution of these 2 biomarkers was different. Therefore the evaluation of catalase and SOD could represent additional relevant parameters in the monitoring of the treatment response.
\end{abstract}

(C) 2019 International Formulae Group. All rights reserved

Keywords: Tuberculosis, HIV, treatment, antioxidant/prooxidant balance, catalase, superoxide dismutase, biomarkers. 


\section{INTRODUCTION}

Tuberculosis is a major public health problem worldwide, causing high morbidity and mortality. It is a bacterial infection caused by Mycobacterium tuberculosis complex. In the third millennium, it remains one of the main challenges with one third of the world's population infected because it is the leading cause of death by a single infectious agent (WHO, 2018).

According to the WHO report, in 2017, 10 million people contracted tuberculosis, $90 \%$ of them adults and $9 \%$ people living with HIV. After Asia, Africa is the second most affected continent, with South Africa and Nigeria being the leading countries. As a result of this infection, $16 \%$ of people died worldwide (WHO, 2018). In Cameroon, 24,905 cases of TB have been reported. Among tuberculosis patients who received HIV screening, $31 \%$ were co-infected. In addition, among the reported cases, the pulmonary form was found in $83 \%$ of cases (WHO, 2018).

During Mycobacterium Tuberculosis (MT) infection, the cellular environment is extremely rich in inflammatory factors, particularly reactive oxygen species (ROS), which are bactericidal molecules. Free radicals can be produced by leukocytes recruited at the site of infection or by the endothelial cell (Huet et Duranteau, 2008). During the inflammatory response, there is a phenomenon classically called "oxygen burst" which corresponds to the massive release of ROS by neutrophil polynuclear cells (Huet et Duranteau, 2008). These free radicals are not only toxic to the pathogen, but also to the host. The damage caused in the host is partly due to the oxidation of amino acids on proteins leading to the formation of carbonyl proteins (Dalvi et al., 2012), resulting in the inhibition of certain enzymatic activities, proteolysis, and immune dysregulation. ROS produced by immune cells to control infection cause oxidative stress (OS). The increase of OS biomarkers due to tuberculosis has been reported in the literature (Taha et Thanoon, 2010; Awodele, 2012; Oyedeli, 2013; Adebimpe, 2015). The disparity in the antioxidant/prooxidant balance observed during tuberculosis can also be demonstrated by the determination of biomarkers. The antioxidant biomarkers constitute a defense against the overproduction of free radicals that contribute to the reduction of oxidative stress induced by infection or anti-tuberculosis treatment. Although studies have been conducted on the profile of antioxidant markers during anti-tuberculosis therapy, grey areas still remain in this area due to many factors related to host, disease and pathogen (Reddy et al., 2004; Moses et al., 2008; Taha et Thanoon, 2010; Mohod et al., 2011; Dalvi et al., 2012). There is paucity of local reports on the status of enzymatic antioxidants related to TB in our country. Thus, the determination of the profile of antioxidant biomarkers could contribute to a better knowledge of mechanisms developed by the host for the antioxidant/prooxidant balance. Moreover, in circumstances where sputum tests are not possible nor contributive, the analysis of these biomarkers appears as a potential monitoring method of the treatment response. The objective of this study was to investigate the effect of first-line antituberculosis therapy on the antioxidant system in tuberculosis patients in a health centre in the city of Yaoundé. Since sputum is not systematically obtained from tuberculosis patients, this study could bring additional information for the monitoring of tuberculosis treatment.

\section{MATERIALS AND METHODS Design}

This prospective cohort study was carried out after obtaining ethical clearance from the regional office of the Ministry of Public Health $\left(\mathrm{N}^{\circ}\right.$ 00352/AP/MINSATE/SG/DRSPC), and the administrative authorizations of Jamot Hospital in Yaoundé, and the Cliniques Universitaires des Montagnes.

\section{Study site}

Participants were recruited in the department of pneumology of Jamot Hospital in Yaoundé (JHY). The recruitment took place from February 01 to April 30, 2018, with a 
minimum follow-up of 05 months for each participant.

The study population consisted of patients with a diagnosis of tuberculosis bacteriologically confirmed. The inclusion criteria were: 1/ any patient with a first episode of active tuberculosis of at least 15 years of age; 2/any patient free of any antituberculosis treatment. The exclusion criteria were: 1/ any pregnant or lactating woman; 2/ any patient with a history of dietary supplement use (vitamin, iron) at the time of the initial assessment; 3/ any patient with a co-existing lung disease or a history of blood transfusion in the 6 months preceding the study.

\section{Procedure}

The recruitment was done in accordance with the selection requirements. The sample size was calculated using the Whitley formula. After ensuring that the patient met the selection criteria, he or she was informed of the purpose of the study and its procedure requiring a follow-up of 5 months $(\mathrm{T} 1=$ before treatment; $\mathrm{T} 1=$ at 2 months of 1st line antituberculosis treatment; $\mathrm{T} 3=$ at 5 months of 1 st line antituberculosis treatment). All participants received antituberculosis treatment from the National Tuberculosis Program, according to the following protocol: 2 months of Rifampicin Isoniazid - Ethambutol - Pyrazinamid, followed by 4 months of Rifampicin and Isoniazid. Once consent was obtained, a pretested questionnaire covering sociodemographic, clinical, and biological data was filled out by each participant.

\section{Clinical and biological sampling}

The following clinical data were obtained: 1/ history (medical and toxicological); $2 /$ clinical signs; $3 /$ biological data (microscopic examination of sputum). For anthropometric parameters, the weight in kilograms was measured using a mechanical scale and the Body Mass Index (BMI) was calculated.

A volume of $10 \mathrm{ml}$ of venous blood was collected from the elbow crease using a vacutainer® needle after asepsis of the puncture site with a cotton pad soaked in alcohol. These samples, taken using dry tubes, were collected at different times, particularly before the initiation of treatment (RifampicinIsoniazid-Ethambutol-Pyrazinamid) (T1), then at two (T2) and five (T3) months after the start of treatment. At T2 and T3 encounters, the patient's weight, the persistence of clinical signs, the result of the sputum microscopy test were also collected. Samples obtained were centrifuged for $5 \mathrm{~min}$ at 2,500 rpm using an IEC CL3 1RMultispeed centrifuge ${ }^{\circledR}$ at Jamot Hospital, then the serum was distributed into four previously labelled $2 \mathrm{ml}$ Eppendorf microtubes (identification code, sampling date). Aliquots were frozen at $-20{ }^{\circ} \mathrm{C}$ for further analysis. Samples were transported using a portable freezer to the Microbiology Laboratory of the Cliniques Universitaires des Montagnes for the analysis of antioxidant activity.

Evaluation of the enzymatic activity of catalase and superoxide dismutase (SOD)

Catalase activity was determined according to Sinha method (Sinha, 1972). In this technique, dichromate is reduced with acetic acid by a heat treatment to chromium acetate, in the presence of $\mathrm{H} 202$ leading to the formation of chromic acid which is an unstable reaction intermediate.

The formula used to calculate Catalase activity was:

$\mathrm{y}=0.0006 \mathrm{x}-0.0013$ (Correlation factor: $\mathrm{R}^{2}=0.9711$ )

Catalase activity was expressed in IU ( $\mu$ moles of $\mathrm{H} 202$ used per minute/ml of serum).

The technique used for the SOD analysis was that of Misra and Fridovich, in which SOD inhibits the auto-oxidation of epinephrine at $\mathrm{pH} 10.2$ (Fridovich, 1975).

The formula used to calculate SOD activity was:

\section{$\underline{\Delta \mathrm{DO} \times \mathrm{Vt} \times 106}$ $4020 \times \mathrm{Vi}$}

$\Delta \mathrm{DO}=$ variation of optical density between 30 sec and $2 \mathrm{~min}$ $\mathrm{Vt}=$ total volume of the solution 
$\mathrm{Vi}=$ total volume of serum

SOD activity was expressed in IU ( $\mu$ moles of H202 used per minute/ml of serum

Catalase and SOD absorbances were read using an ELISA LDR 2100C microplate reader from Laboratoires Humeau Laboratories at 530 and $480 \mathrm{~nm}$ respectively.

\section{Statistical analysis}

Data analysis was performed using SPSS version 16 (IBM, New York, US) and figures were created using GraphPad 5.0 (GraphPad Software Inc, CA, US). The qualitative variables were expressed in numbers and percentages. For the numerical variables, the normal distributions were represented by their mean and standard deviation or median (interquartile range). The comparison of the mean values was carried out by variance analysis (repeated measurement ANOVA). The McNemar test was used for the analysis of the matched variables. A value of $\mathrm{p}<0.05$ was considered statistically significant.

\section{RESULTS}

In this study, 75 participants met the eligibility criteria. The study population was composed of 50 men and 25 women (sex ratio of 2). The mean age of participants was $34+$ 13 years (extremes: 16 and 76 years). Additionally, the population was slightly more constituted of single individuals (54.67\%) (Table 1).

\section{Clinical manifestations at the confirmation of tuberculosis}

The study population was distributed according to the forms of tuberculosis and their comorbidities' as seen in Table 2. The majority of participants had a pulmonary tuberculosis (88\%). A HIV-tuberculosis coinfection was present in $16 \%$ of participants. In total, $28 \%(21 / 75)$ of participants were smokers and $46 \%$ (35/75) were alcohol consumers.

The profile of clinical signs was assessed as shown in Table 3. The most common clinical signs were cough $(86.6 \%)$, weight loss $(73.3 \%)$ and asthenia (64\%) with an average duration of symptoms of $11+8$ weeks.

\section{Clinical manifestations in participants during anti-tuberculosis treatment}

The mean weight was $61.83+11.89$ $\mathrm{kg}, 63.43+11.24 \mathrm{~kg}$ and $67.03+11.71 \mathrm{~kg}$ at $\mathrm{T} 1, \mathrm{~T} 2$ and $\mathrm{T} 3$ respectively with a statistically significant variation over time $(\mathrm{p}=0.0195)$. In addition, the body mass index increased from $21.10+3.25$ to $22.89+3.12$ between $\mathrm{T} 1$ and $\mathrm{T} 3(\mathrm{p}=0.0008)$.

Between tuberculosis confirmation and the end of the 5th month of antituberculosis treatment, the frequency of participants with a negative microscopy test increased from $29.33 \%$ to $93.33 \%$.

\section{Antioxidant biomarkers}

Concerning enzymatic antioxidant markers, activities of catalase and SOD were analyzed taking into consideration clinical parameters as well as shown in Table 4 .

At the time of tuberculosis diagnosis, the activity of antioxidant markers did not vary according to the nutritional status. Even though, enzymatic activities of Catalase and SOD were higher among participants with positive bacillary load, the difference was not significant (Catalase: $p=0.513$; SOD: $\mathrm{p}=0,642)$. There was no influence of the duration of clinical signs on the activities of Catalase $(p=0.403)$ and SOD $(p=0.609)$. Moreover, there was no effect of the form of tuberculosis on the activity of enzymatic antioxidant biomarkers (Catalase: $\mathrm{p}=0.732$; SOD: $\mathrm{p}=0.727$ ).

\section{Evolution of antioxidant biomarkers}

The mean activity of catalase was 3588 + 244.8 IU [extremes: 2982 - 4107], $2541+$ 590.7 IU [extremes: 1417 - 3672] and $3049+$ 204.4 IU [extremes: 2582 - 3429] at T1, T2 and $\mathrm{T} 3$ respectively (Figure 2 ). The evolution was significant $(\mathrm{p}<0.0001)$. The mean SOD activity was $0.041+0.021$ IU [extremes: 0 0.09], $0.046+0.021 \mathrm{IU}$ [extremes: $0.01-$ 0.11 ] and $0.062+0.040$ IU [extremes: 0 0.16 ] at $\mathrm{T} 1, \mathrm{~T} 2$ and $\mathrm{T} 3$ respectively (Figure 3 ). The change was significant $(\mathrm{p}=0.0112)$. 


\section{Catalase}

The activity of Catalase was analysed according to the HIV (Figure 4) and the smoking (Figure 5) status.

According to the HIV status, the curves of catalase's activity were superposable over the time with a threshold at T2 (HIV positive: $2576+141,1 \mathrm{IU}$; HIV negative: $2591+74,92 \mathrm{IU})$.

The curves of catalase's activities according to the smoking status were also superposable over the time with a threshold at T2 (smokers: $2456+117,5 \mathrm{IU}$ versus non smokers: $2632+95,05$ IU) with $\mathrm{p}=0.437$ at $\mathrm{T} 1, \mathrm{p}=0.542$ at $\mathrm{T} 2$ and $\mathrm{p}=$ 0.675 at $\mathrm{T} 3$.

\section{SOD}

The activity of SOD was also assessed according to HIV (Figure 6) and smoking (Figure 7) status. The levels of
SOD's activity tended to increase globally from $\mathrm{T} 1$ to $\mathrm{T} 3$.

SOD's activities were superposable at $\mathrm{T} 1(\mathrm{p}=0.541)$ et $\mathrm{T} 2(\mathrm{p}=0.678)$. However , even though the difference was not significant, SOD activity of HIV negative participants was higher in comparison to HIV positive participants at $\mathrm{T} 3(\mathrm{p}=0.9)$.

At T1, the SOD's activities according to the smoking status were superposable $(\mathrm{P}=0.521)$. Hovewer, smokers had higher activities of SOD observed at T2 et T3, even though the difference was not significant $(\mathrm{p}=0.478 ; \mathrm{T} 3: \mathrm{p}=0.371)$.

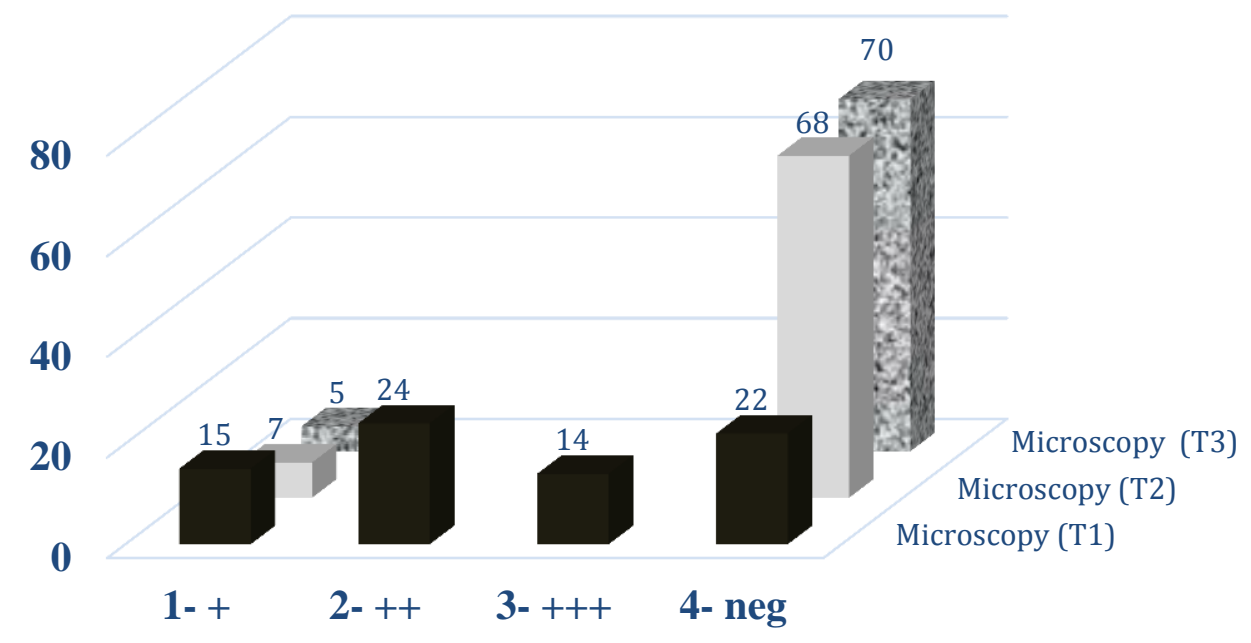

Microscopy (T1) Microscopy (T2) a Microscopy (T3)

Microscopy (T1): microscopy result before treatment

Microscopy (T2): microscopy result at the $2^{\text {nd }}$ month of antituberculosis treatment

Microscopy (T3): microscopy result at the 5th month of antituberculosis treatment

Figure 1: Distribution of participants according to the bacillary load during the antituberculosis treatment. 
Table 1: Distribution of the population according to socio-demographic variables.

\begin{tabular}{lll}
\hline Sex & $\mathrm{n}$ & \\
\hline & 50 & Percentage \\
\hline Men & 25 & 66.67 \\
Women & & 33.33 \\
\hline Age & 19 & \\
\hline$<25$ & 27 & 25.33 \\
$25-34]$ & 9 & 36.00 \\
{$[35-44]$} & 11 & 12.00 \\
{$[45-54]$} & 8 & 14.67 \\
{$[55-64]$} & 1 & 10.67 \\
$>64$ & & 1.33 \\
\hline \multicolumn{1}{c}{ Marital status } & 41 & \\
\hline Single & 19 & 54.67 \\
Married & 3 & 25.33 \\
Widowed & 11 & 4.00 \\
Coupled & 1 & 14.67 \\
Divorced & & 1.33 \\
\hline
\end{tabular}

Table 2: Distribution of the study population according to the site of tuberculosis and comorbidities at the time of tuberculosis confirmation.

\begin{tabular}{lll}
\hline Site of Tuberculosis & $\mathrm{n}$ & \\
\hline & 64 & Percentage \\
\hline Pulmonary & 9 & 85.33 \\
Extrapulmonary & 2 & 12.00 \\
Multifocal & & 2.67 \\
\hline HIV status & 63 & 84.00 \\
\hline Negative & 12 & 16.00 \\
Positive & & \\
\hline Diabetes status & 74 & 98.67 \\
\hline Negative & 1 & 1.33 \\
Positive & & \\
\hline Alcoholism & 40 & 53.33 \\
\hline No & 35 & 46.67 \\
Yes & & 72.00 \\
\hline Smoking status & 54 & 28.00 \\
\hline No & 21 & \\
Yes & 2250
\end{tabular}


Table 3: Distribution of clinical signs among participants at time of tuberculosis confirmation.

\begin{tabular}{lll}
\hline Clinical signs & n & Percentage \\
\hline cough & 65 & 86.66 \\
Weight loss & 55 & 73.33 \\
Asthenia & 48 & 64.00 \\
Fever & 46 & 61.33 \\
Dyspnea & 42 & 56.00 \\
Chest pain & 33 & 44.00 \\
Nocturnal Sudation & 30 & 40.00 \\
Hemoptysis & 14 & 18.66 \\
\hline Duration of Signs & & \\
[Weeks] & $11+8[1-48]$ & \\
Mean and Standard Deviation & & \\
\hline
\end{tabular}

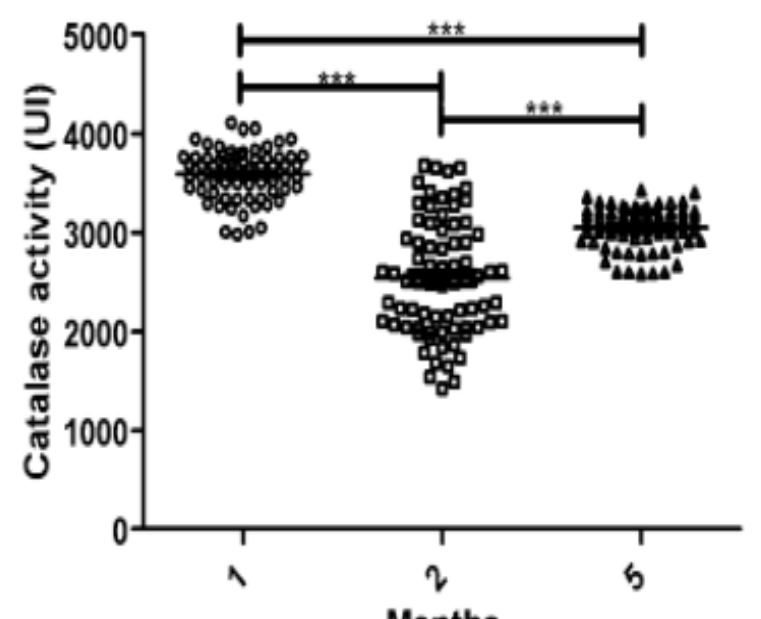

1: catalase activity at $\mathrm{T} 1$

2: catalase activity at $\mathrm{T} 2$

5: catalase activity at $\mathrm{T} 3$

***: $\mathrm{P}<0,0001$

IU: $\mathrm{micromol} / \mathrm{min} / \mathrm{ml}$ serum

Figure 2: Evolution of Catalase activity over time (T1, T2, T3).

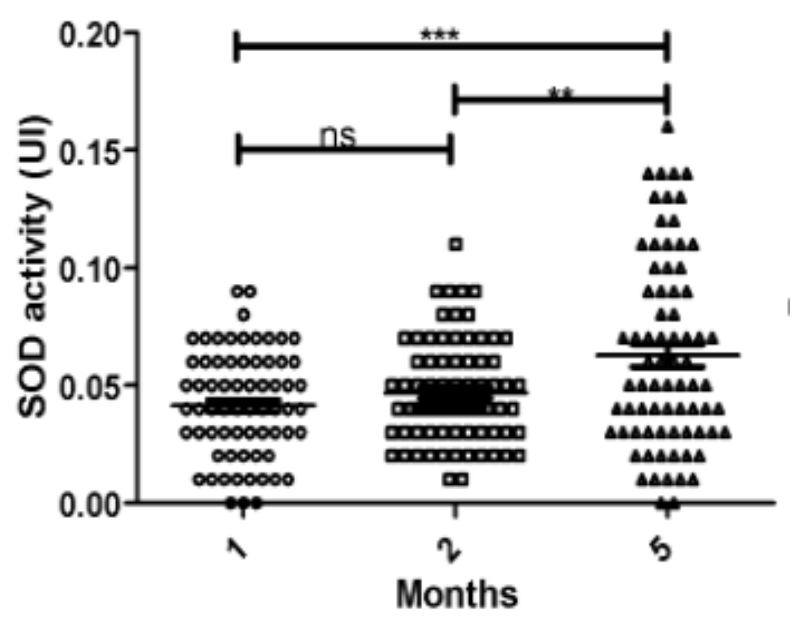

1: SOD activity at $\mathrm{T} 1$

2: SOD activity at $\mathrm{T} 2$

5: SOD activity at $\mathrm{T} 3$

**: $\mathrm{P}<0,01$

$* * *: \mathrm{P}<0,0001$

$\mathrm{IU}: \mathrm{micromol} / \mathrm{min} / \mathrm{ml}$ serum

Figure 3: Evolution of SOD activity over time (T1, T2, T3). 
Table 4: Antioxidant enzyme activity according to host nutritional status and disease variables at the time of TB confirmation.

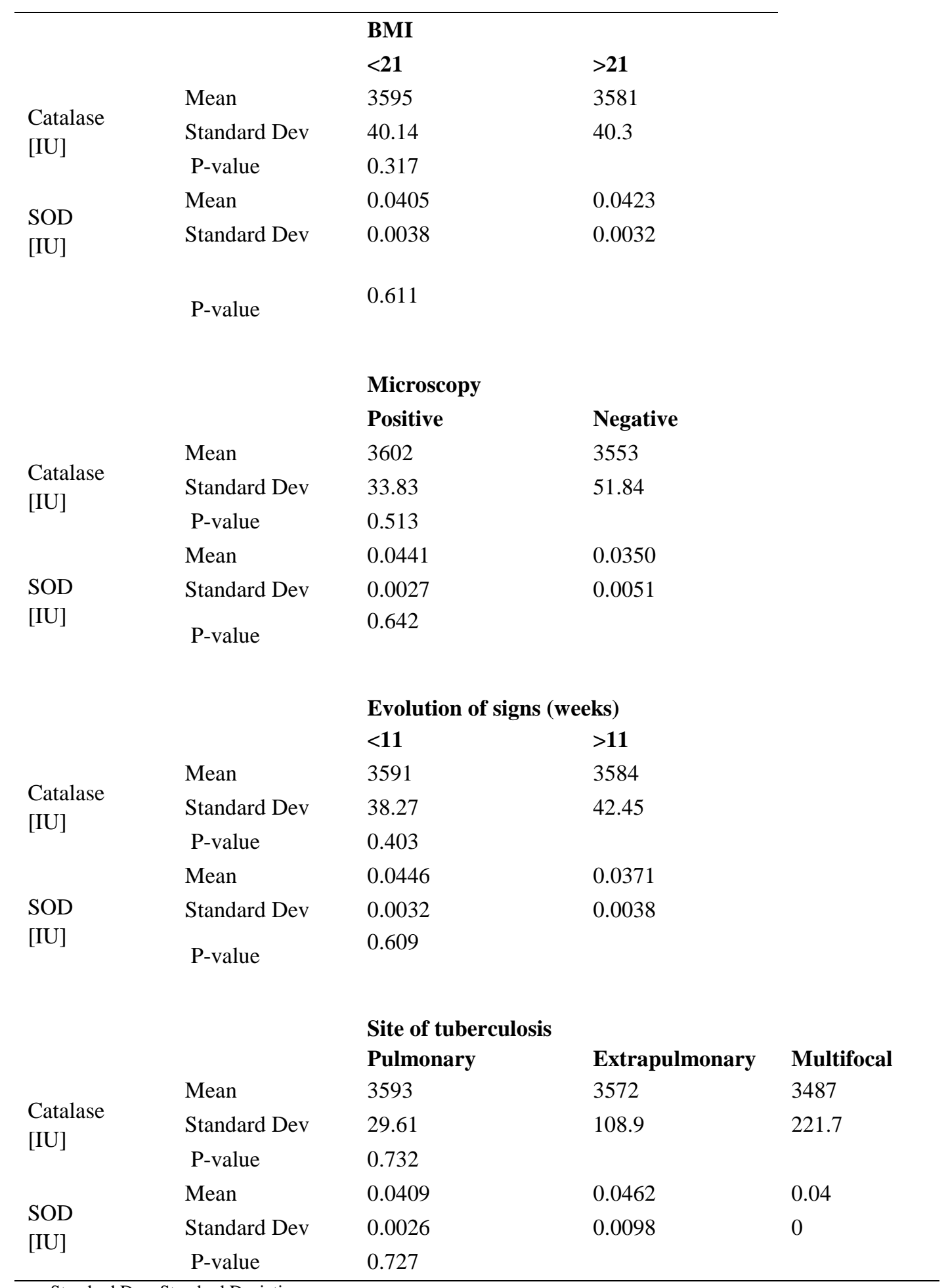




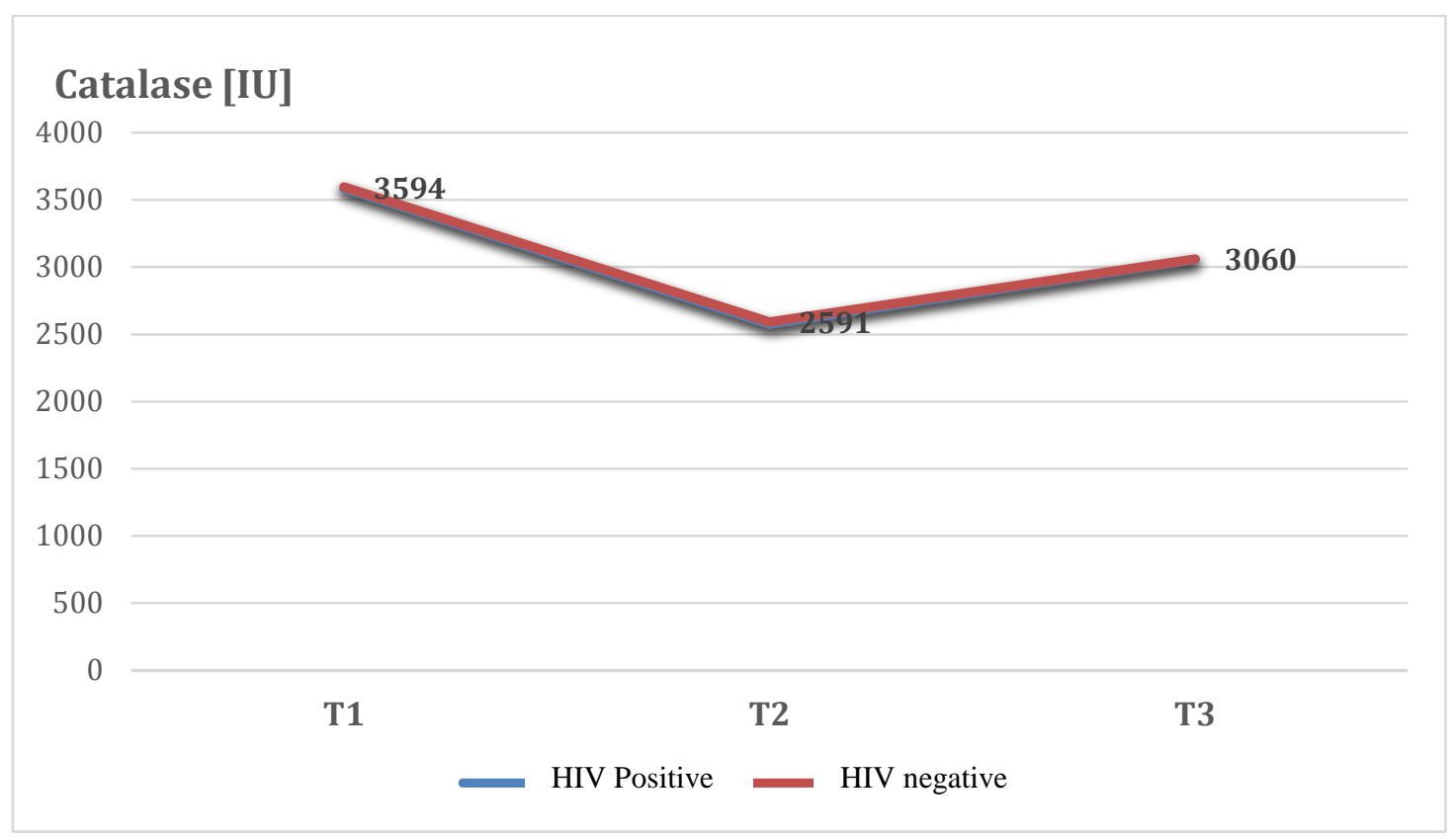

IU: $\mathrm{micromol} / \mathrm{min} / \mathrm{ml}$ serum

At T1: $\mathrm{p}=0.281$

At $\mathrm{T} 2: \mathrm{p}=0.467$

At T3: $\mathrm{p}=0.55$

Figure 4: Evolution of Catalase activity of antioxidant markers according to HIV status.

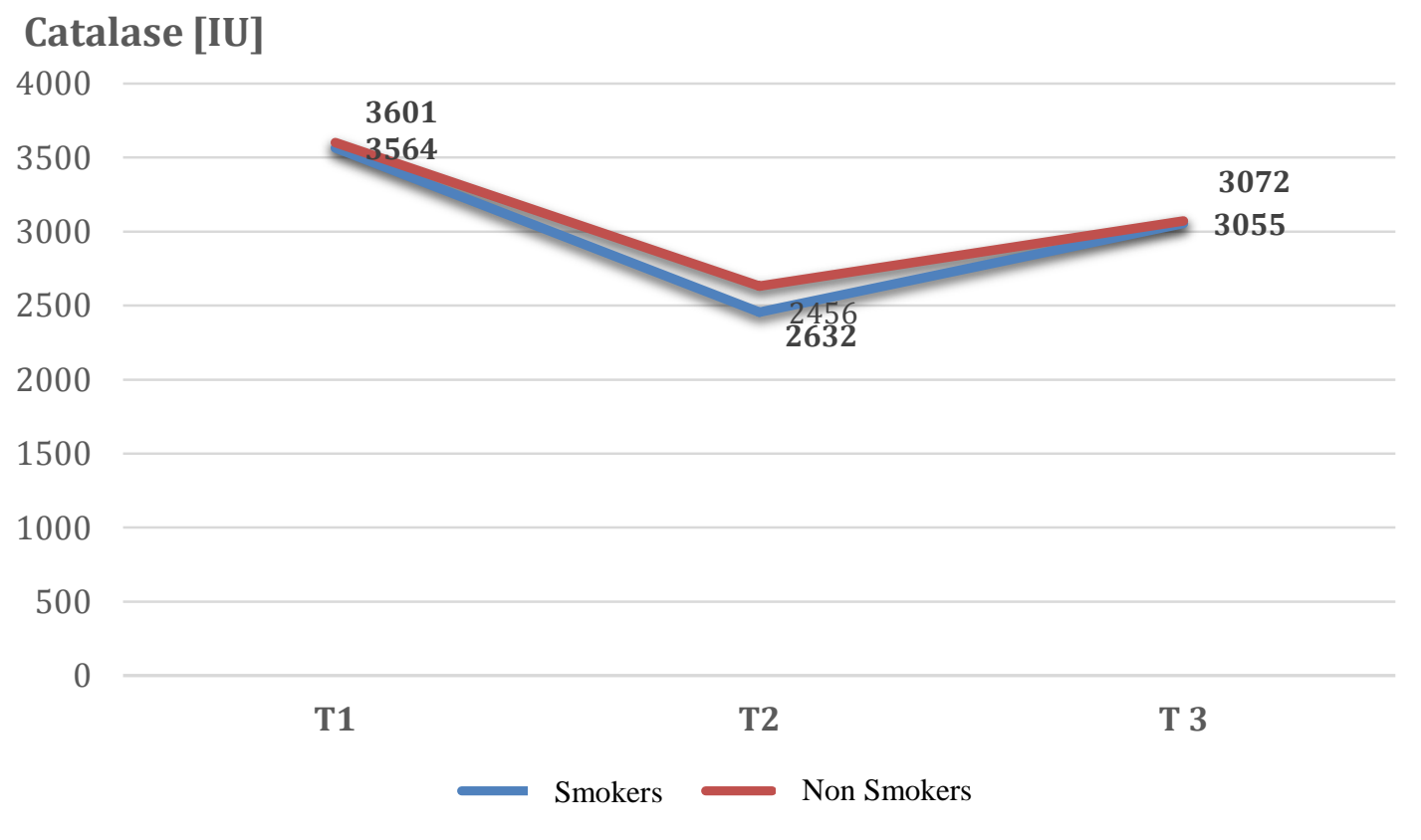

IU: $\mathrm{micromol} / \mathrm{min} / \mathrm{ml}$ serum

At T1: $\mathrm{p}=0.437$

At $\mathrm{T} 2: \mathrm{p}=0.542$

At T3: $\mathrm{p}=0.675$

Figure 5: Evolution of Catalase activity according to smoking status. 


\section{SOD [IU]}

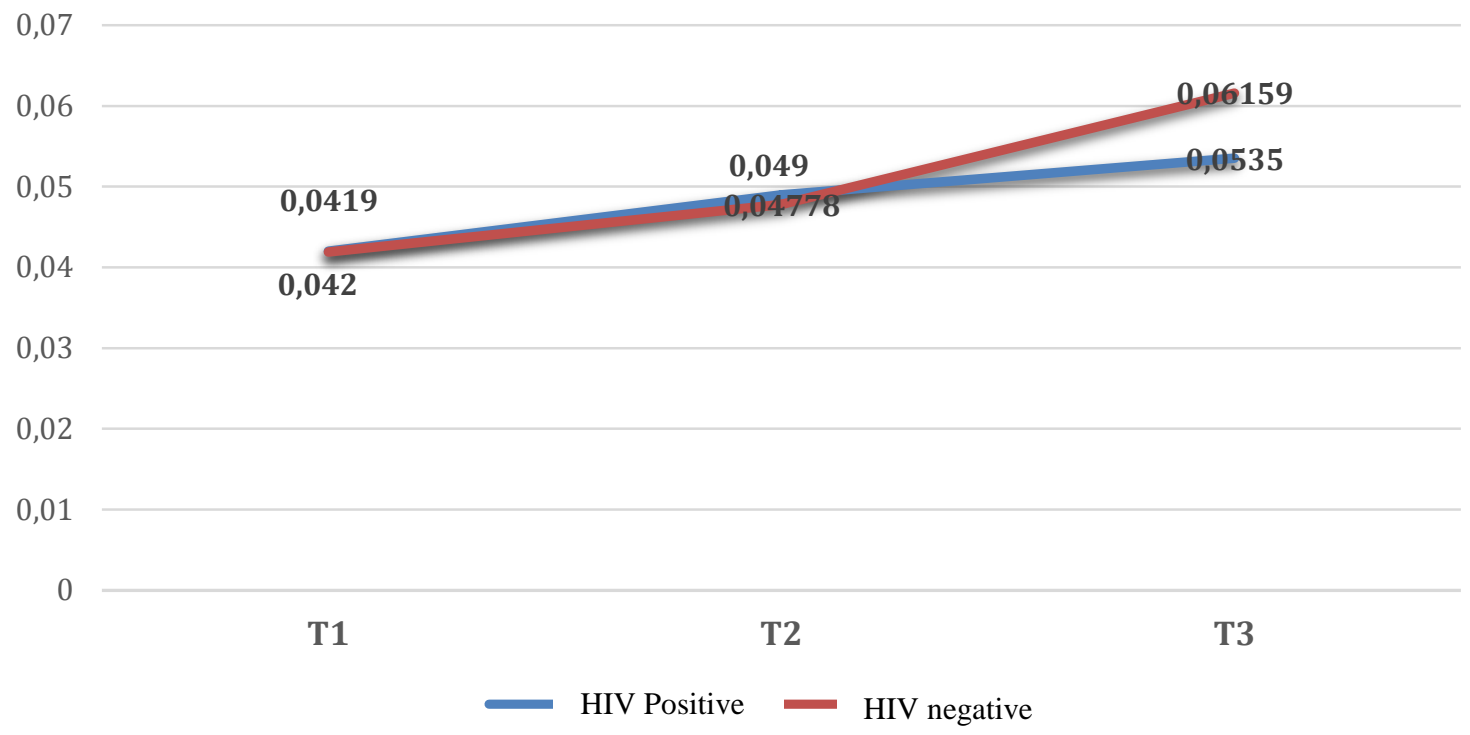

IU: $\mathrm{micromol} / \mathrm{min} / \mathrm{ml}$ serum

At T1: $\mathrm{p}=0.54$

At $\mathrm{T} 2: \mathrm{p}=0.67$

At T3: $\mathrm{p}=0.9$

Figure 6: Evolution of SOD activity according to VIH Status.

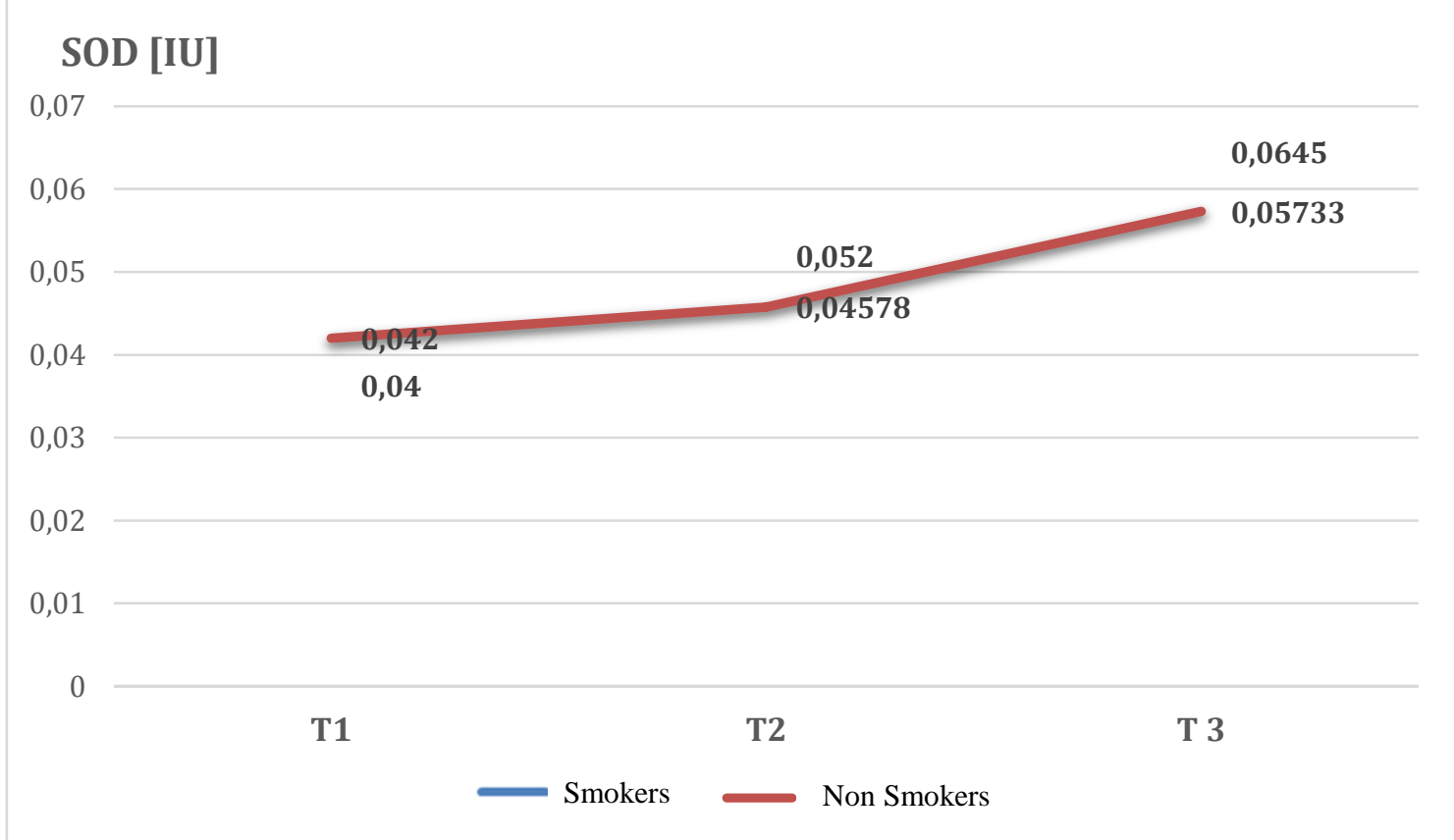

IU: $\mathrm{micromol} / \mathrm{min} / \mathrm{ml}$ serum

At $\mathrm{T} 1: \mathrm{p}=0.521$

At $\mathrm{T} 2: \mathrm{p}=0.468$

At T3: $\mathrm{p}=0.371$

Figure 7: Evolution of SOD activity according to smoking status. 


\section{DISCUSSION}

Pulmonary tuberculosis is one of the major causes of morbidity and mortality in developing countries (WHO, 2018). MT is an intracellular pathogen that replicates in host macrophages. In response, the host cell generates huge amounts of ROS to kill the bacteria, resulting in oxidative stress. This stress can be assessed by the dosage of specific markers such as pro-oxidants or antioxidants produced as a result of the infection and/or treatment. The purpose of our study was to determine the effect of first-line antituberculosis antibiotic therapy on oxidative stress antioxidant enzymes (CAT and SOD) during the first five months of treatment. The study population was essentially young with a mean age of $34+13$ years. The most represented age group was $25-34$ years $(36 \%)$. This group is the most active and also subject to migration, making it a risk group. These results are superimposed on those found in other studies conducted in Cameroon (Njouma et al., 2015: 36 years; Pefura et al., $2014: 33$ years; Noubom et al., 2013: 33 ans) (Njouma et al., 2015; PefuraYone et al., 2014; Noubom et al., 2013). The population was predominantly male $(66 \%)$. Indeed, tuberculosis regardless of race or ethnicity is more frequent in men than in women (Kyu et al., 2018). Other studies on tuberculosis in our environment also report this male predominance $(64,8 \%$ by Noubom et al. (2013); 73\% by Pefura-Yone et al. (2014); $59 \%$ by Pefura-Yone et al. (2015); 62\% by Djouma et al. (2015)). This high proportion of men is explained by the exposure to risk factors as tobacco (O'Leary et al., 2014) and alcohol (Nelson et al., 2008). More than a quarter of the participants were smokers. Moreover, almost half of the study population consumed alcohol. Our results related to smoking habits are consistent with those of Pefura-Yone et al. (2014), who had $25.6 \%$ of smokers at the time of tuberculosis diagnosis. Smoking and alcoholism have also been reported to be factors associated with tuberculosis by Meriki in North-West and South-West regions of Cameroon (Meriki et al., 2013). The justification of this association can be their capacity to impair the immune system (Nelson et al., 2008; O’Leary et al., 2014; Kyu et al., 2018).

TB/HIV co-infection was noted in $16 \%$ of the participants in our series. These results are lower than those found in other studies carried out in Cameroon such as those of Pefura-Yone et al. (2014) (27.9\%) and Djouma et al. (2015) (23.5\%). This can be explained by the decrease in Cameroon's HIV infection rate. According to WHO, the population of TB-HIV co-infected patients in Cameroon dropped from 34\% in 2016 (WHO, 2017) to $31 \%$ in 2017 (WHO, 2018).

In order of frequency, the most common clinical signs were: coughing, weight loss, and asthenia. The frequency of signs is thought to be related to the site of tuberculosis, which was mainly pulmonary. Pulmonary tuberculosis is the main form found worldwide (WHO, 2018). Pefura-Yone et al. (2014) found a different frequency for the different clinical signs, particularly hemoptysis $(22.1 \%$ versus $14.9 \%)$, dyspnea (27.9\% versus $57.5 \%$ ), and fever ( $86 \%$ versus $67.8 \%)$. In our study, the pulmonary form (84\%) was mixed with extra-pulmonary $(12.6 \%)$ and multifocal (3.4\%) diseases, unlike Pefura-Yone et al. (2014), who had recruited only pulmonary forms of tuberculosis in their study.

To prevent oxidative damage caused by the production of ROS, there are enzymatic antioxidants such as SOD, Glutathione Peroxidase (GPx), catalase, Glutathione -STransferase (GST) that have a protective role in the host. SOD, a metalloprotein containing zinc and copper (cytosolic and extracellular forms) or magnesium (mitochondrial form), is one of the antioxidant enzymes that protect against oxidative stress by converting the superoxide radical into $\mathrm{H}_{2} \mathrm{O}_{2}$. It is a metalloprotein that represents one of its first lines of defense. Our study shows that its pretreatment activity (T1) was statistically low compared to that obtained after 5 months of treatment (T3). This low $\mathrm{T} 1$ activity is the result of the increasing production of superoxide anion, which is a consequence of the infection. This leads to its exhaustion with catalase activity compensation which contributes to the degradation of hydrogen 
peroxide produced by SOD. These results are superimposed on those of Reddy et al. (2004). SOD activity increased insignificantly at the end of the initial treatment phase (T2). This can be explained by the inflammatory state that contributed to the growth of oxidative stress during the intensive phase of antituberculosis therapy, resulting in a rise of antioxidant activity that lasted for up to 5 months of treatment.

During the treatment, SOD activity is reported to be related to the destruction of mycobacteria due to chemotherapy (Nnodim et al., 2011). In our study, we noted that catalase activity was higher at the time of tuberculosis diagnosis, than the ones obtained during phase $\mathrm{T} 2$, and phase $\mathrm{T} 3$ of the treatment. Its evolution profile is different from the one reported in the literature, where a progressive increase in catalase activity is described during the first two months of antituberculosis antibiotic therapy (Sigal et al., 2017). The level of its activity before the initiation of treatment reflects the high reserve of catalase for the defense against EROs produced by the host facing the infection. However, a decrease in activity is noted during the intensive treatment phase, which might be the manifestation of oxidative stress induced by anti-tuberculosis therapy (Mokondjimobe et al., 2012). Moreover, the OS produced by the host is involved in modulating the effectiveness of antituberculosis treatment. Anti-tuberculosis molecules, particularly Isoniazid, are prodrugs that are activated inside the organism of the host. The activation of anti-tuberculosis molecules is due to the action of MT KatG, which is overexpressed in the presence of a significant OS in the environment (Madhur et al., 2018). Thus, the rise of oxidants is an important element for the effectiveness of anti-tuberculosis treatment. After 5 months of treatment, the activity of SOD and catalase is significantly high. At this stage, this growth can no longer be explained by the inflammatory process or by the treatment. However, this may be justified by a recovery of the antioxidant mechanisms of the host during the healing phase.
The evolution of the catalase activity and SOD were both superimposable regardless of the HIV status of the participants a tT1 et T2. However, we noted a rise of SOD activity in HIV negative participants at T3, even though it was not significant. HIV-TB co-infection has been implicated as a factor contributing to the decrease in antioxidant activity (Awodele et al., 2012). In a study conducted by Rajopadhye (2017), he found that antioxidant activity of SOD increased significantly in the group of TB-HIV positive participants. This was not observed in tuberculosis-HIV negative participants. In contrast, catalase activity decreased significantly in treated participants (Rajopadhye et al., 2017). In the literature, it is reported that the rise of OS is due to the coexistence of chronic inflammation, antiretroviral treatment, and malnutrition in TB-HIV co-infected patients (Gil-del Valle et al., 2017). Thus our results are contrary to those of Rajopadhye and can be explained by the recovery of antioxidant capacity at the $5^{\text {th }}$ month of treatment. In our study, neither the duration of symptoms nor microscopy tests influenced the activity of catalase and SOD. This is contrary to the results of Mohod (2011) who found in his series that a highly positive microscopic test was associated with low antioxidant activity of SOD (Mohod et al., 2011). Thus, although the number of pathogens found on microscopic results is a manifestation of the infection's severity, it had no effect on the activity of antioxidant enzymes.

Even though the main limitation was the loss of some participants, this work provides us with information on the evolution of antioxidant markers in TB patients in our context. Further studies on the antioxidant/pro-oxidant balance are needed to strengthen our knowledge.

\section{Conclusion}

In this study, tuberculosis was mainly pulmonary (85.3\%) and affected mostly men. HIV-TB co-infection was found in $16 \%$ of participants. Predominant signs were coughing, weight loss and asthenia. SOD activity increased significantly between the 
time of diagnosis and the 5th month of treatment. Catalase activity varied significantly with the lowest threshold reached at the 2nd month of treatment. However, the activity profile of antioxidant enzymes was not influenced by host-related and diseaserelated parameters. Therefore the evaluation of catalase and SOD may represent an additional tool in the monitoring of $\mathrm{TB}$ treatment.

\section{COMPETING INTERESTS}

The authors declare that they have no competing interests.

\section{AUTHORS' CONTRIBUTIONS}

All authors made a substantial contribution to the concept or design of the work; or acquisition, analysis or interpretation of data, drafted the article or revised it critically for important intellectual content, and approved the version to be published.

\section{ACKNOWLEDGEMENTS}

We want to thank the staff of the microbiology laboratory of the Cliniques Universitaires des Montagnes. We thank all of the participants who consented to take part in this study.

\section{REFERENCES}

Awodele O, Olayemi SO, Nwite JA, Adeyemo TA. 2012. Investigation of the levels of oxidative stress parameters in HIV and HIV-TB co-infected patients. $J$ Infect Dev Ctries, 6: 79-85. DOI: 10.3855/jidc. 1906

Dalvi SM, Patil VW, Ramraje NN. 2012. The roles of glutathione, glutathione peroxidase, glutathione reductase and the carbonyl protein in pulmonary and extra pulmonary tuberculosis. Journal of Clinical and Diagnostic Research, 6(9): 1462-1465.

DOI: $10.7860 / J C D R / 2012 / 4410.2533$

Djouma F, Noubom M, Ateudjeu J, Donfack H. 2015. Delay in sputum smear conversion and outwomes of smearpositive tuberculosis in patients: a retrospective cohort study in Bafoussam, Cameroon. BMC Infectious Diseases, 15:139.
DOI: https://doi.org/10.1186/s12879015-0876-1

Fridovich I. 1975. Superoxide Dismutases. Аnnu Rev Biochem, 44: 147-159. DOI: https://doi.org/10.1146/annurev.bi. 44.070175.001051

Gil-del Valle L, Bareala Nunez A, Pomiez Suarez O, Gravier-Hernandez R, Bermidez-Alfonso Y, HernandezRequejo D, et al. 2017. Biomarkers of Redox Balance in Tuberculosis- Human Immunodeficiency Virus Co-Infected Cuban Patients. ARC Journal of AIDS, 2(1):1-11. DOI:10.20431

Global Tuberculosis Report 2017. https://www.who.int/tb/publications/glob al_report/gtbr2017_main_text.pdf.

Huet O, Duranteau J. 2008. Dysfonction endothéliale: rôle des radicaux libres : Réanimation, 17: 387-392. DOI:10.1016/j.reaurg.2008.03.020

Kyu, Hmwe $\mathrm{H}$ et al. 2018. The global burden of tuberculosis: results from the Global Burden of Disease Study 2015. The Lancet Infectious Diseases, 18(3): 261 284.

DOI: https://doi.org/10.1016/S14733099(17)30703-X

Madhur D. Shastri, Shakti Dhar Shukla, Wai Chin Chong, et al. 2018. Role of Oxidative Stress in the Pathology and Management of Human Tuberculosis. Oxidative Medicine and Cellular Longevity, 2018: 10 pages. DOI: https://doi.org/10.1155/2018 17695364.

Meriki HD, Tufon KA, Atanga PN, AneAnyangwe IN, Damian N, Anong DN, Cho-Ngwa F, et al. 2013. Drug resistance profiles of Mycobacterium tuberculosis complex and factors associated with drug resistance in the Northwest and Southwest Regions of Cameroon. PLoS One, 8(10): e77410. DOI: 10.1371/journal.pone.0077410

Mohod K, Dhok A, Kumar S. 2011. Status of Oxidants and Antioxidants in Pulmonary Tuberculosis with varying Bacillary Load. Journal of Experimental Sciences, 2(6): 35-37. DOI: https://udatepublishing.com/journal/inde x.php/.../1828 
Mokondjimobe E, Longo-mbenza B, Akiana J, Ndalla U, Dossou-yovo R, Mboussa J et al. 2012. Biomarkers of Oxidative Stress and Personalized Treatment of Pulmonary Tuberculosis: Emerging Role of Gamma-Glutamyltransferase. Advances in Pharmacological Sciences, 2012: 7 pages. DOI: https://doi.org/10.1155/2012/465634.

Moses AO, Emmanuel OO, Ganiyu AO, Fidelis AA, Dickson AO. 2008. Assessment of antioxidants and nutritional status of pulmonary tuberculosis patients in Nigeria. European Journal of General Medicine, 5(4): 208-211.

Nelson S, Zhang P, Bagby GJ, Happel KI, Raasch CE. 2008. Alcohol abuse, immunosuppression, and pulmonary infection. Current Drug Abuse Reviews, 1(1): 56-67.

Nnodim J, Anyadoh, NwosuNjoku E. 2011. The antioxidant status and lipid peroxidation product of newly diagnosed and 6 week's follow-up patients with pulmonary tuberculosis in Owerri, Imo state, Nigeria. Asian Pacific Journal of Tropical Disease, 2011: 292-294. DOI: 10.1016/S2222-1808(11)60069-8

Noubom M, Nembot FD, Donfack H, Mfin PS, Tchasse F. 2013. Caractéristiques des patients tuberculeux à l'ouest Cameroun: 2000-2009 [Characteristics of TB patients in west Cameroon: 20002009]. The Pan African Medical Journal, 16: $39 . \quad$ DOI: 10.11604/pamj.2013.16.39.2860

Oyedeji SO, Adesina, AA, Oke OT, Oguntuase NR, Esan A. 2013. Oxidative stress and lipid profile status in pulmonary tuberculosis patients in South Western Nigeria. Greener Journal of Medical Sciences, 3(6): 228-232.

O'Leary SM, Coleman, MM, Chew WM, Morrow C, McLaughlin AM, Gleeson LE, O'Sullivan MP, Keane J. 2014. Cigarette smoking impairs human pulmonary immunity to Mycobacterium tuberculosis. American Journal of Respiratory and Critical Care
Medicine, 190(12): $\quad$ 1430-1436. DOI: https://doi.org/10.1164/rccm.201407$1385 \mathrm{OC}$

Pefura-Yone EW, Kengne A, Kuaban C. 2014. Non conversion of sputum culture among patients with smear positive pulmonary tuberculosis in Cameroon: a prospective cohort study. BMC infectious Diseases, 14: 138 . DOI: https://doi.org/10.1186/1471-2334-14138

Pefura-Yone EW, Kuaban C, Assamba-Mpom SA, Moifo B, Kengne AP. 2015. Derivation, validation and comparative performance of simplified chest $\mathrm{x}$-ray score for assessing and comparative performance of a simplified chest-X- ray score for severity and outcome of pulmonary tuberculosis. Clin Respi J, 9: 157-164.

Rajopadhye SH, Mukherjee SR, Chowdhary AS, Dandekar SP. 2017. Oxidative Stress Markers in Tuberculosis and HIV/TB Co-Infection. J Clin Diagn Res., 11(8): $\quad \mathrm{BC} 24-\mathrm{BC} 28 . \quad \mathrm{DOI}$ : 10.7860/JCDR/2017/28478.10473.

Reddy YN, Murthy S V, Krishna DR, Prabhakar MC. 2004. Role of free radicals and antioxidants in tuberculosis patients. Indian J Tuberc, 51: 213-218.

Sigal GB, Segal MR, Mathew A, Jarlsberg L, Wang M, Barbero $S$ et al. 2017. Biomarkers of tuberculosis severity and treatment effect: A directed Screen of 70 host markers in a randomized clinical trial. EBioMedicine, 2017. DOI: https//doi.org/10.16/j.ebiom.2017.1 0.018

Sinha AK. Colorimetric assay of catalase. 1972. Anal Biochem, 47: 389-394. DOI: https://doi.org/10.1016/00032697(72)90132-7

Taha DA, Thanoon IA-J. . 2010. Antioxidant status, C-reactive protein and iron status in patients with pulmonary tuberculosis. Sultan Qaboos Univ Med J, 10: 361-9.

WHO. 2018. Global tuberculosis report 2018. World Health Organization. https://www.who.int/tb/publications/glob al_report/en/ 